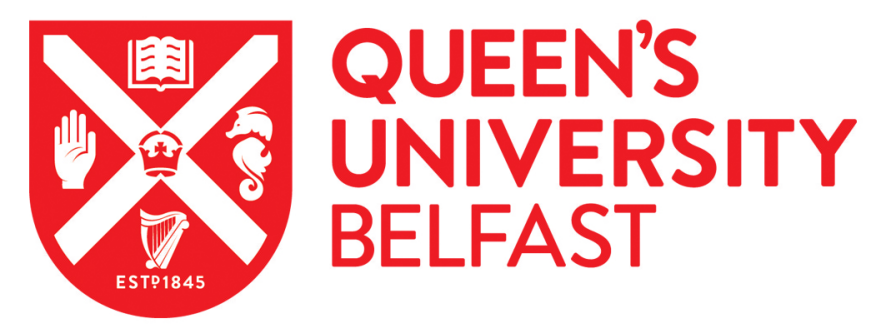

\title{
A Comparison of the Degradation Behaviour of 3D Printed PDLGA Scaffolds incorporating Bioglass or Biosilica.
}

Han, R., Buchanan, F., Ford, L., Julius, M., \& Walsh, P. (2020). A Comparison of the Degradation Behaviour of 3D Printed PDLGA Scaffolds incorporating Bioglass or Biosilica. Materials Science and Engineering C: Materials for Biological Applications. https://doi.org/10.1016/j.msec.2020.111755

Published in:

Materials Science and Engineering C: Materials for Biological Applications

Document Version:

Peer reviewed version

Queen's University Belfast - Research Portal:

Link to publication record in Queen's University Belfast Research Portal

Publisher rights

Copyright 2020 Elsevier

This manuscript is distributed under a Creative Commons Attribution-NonCommercial-NoDerivs License

(https://creativecommons.org/licenses/by-nc-nd/4.0/), which permits distribution and reproduction for non-commercial purposes, provided the author and source are cited

\section{General rights}

Copyright for the publications made accessible via the Queen's University Belfast Research Portal is retained by the author(s) and / or other copyright owners and it is a condition of accessing these publications that users recognise and abide by the legal requirements associated with these rights.

Take down policy

The Research Portal is Queen's institutional repository that provides access to Queen's research output. Every effort has been made to ensure that content in the Research Portal does not infringe any person's rights, or applicable UK laws. If you discover content in the Research Portal that you believe breaches copyright or violates any law, please contact openaccess@qub.ac.uk. 


\section{Journal Pre-proof}

A Comparison of the Degradation Behaviour of 3D Printed PDLGA Scaffolds incorporating Bioglass or Biosilica

R. Han, F. Buchanan, L. Ford, M. Julius, P.J. Walsh

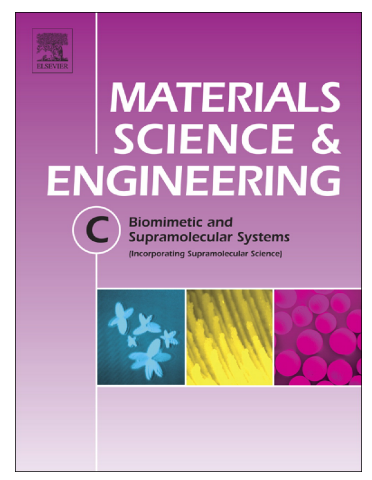

PII:

S0928-4931(20)33674-2

DOI: https://doi.org/10.1016/j.msec.2020.111755

Reference:

MSC 111755

To appear in:

Materials Science \& Engineering $C$

Received date:

13 August 2020

Revised date:

21 October 2020

Accepted date:

21 November 2020

Please cite this article as: R. Han, F. Buchanan, L. Ford, et al., A Comparison of the Degradation Behaviour of 3D Printed PDLGA Scaffolds incorporating Bioglass or Biosilica, Materials Science \& Engineering C (2020), https://doi.org/10.1016/ j.msec.2020.111755

This is a PDF file of an article that has undergone enhancements after acceptance, such as the addition of a cover page and metadata, and formatting for readability, but it is not yet the definitive version of record. This version will undergo additional copyediting, typesetting and review before it is published in its final form, but we are providing this version to give early visibility of the article. Please note that, during the production process, errors may be discovered which could affect the content, and all legal disclaimers that apply to the journal pertain.

(C) 2020 Published by Elsevier. 
Title: A Comparison of the Degradation Behaviour of 3D Printed PDLGA Scaffolds incorporating Bioglass or Biosilica.

Authors: R. $\operatorname{Han}^{1}$, F. Buchanan ${ }^{2}$, L. Ford ${ }^{1}$, M. Julius ${ }^{3}$, PJ Walsh ${ }^{1,2}$

${ }^{1}$ School of Chemistry \& Chemical Engineering, Queen's University Belfast, ${ }^{2}$ School of Mechanical \& Aerospace Engineering, Queen's University Belfast, UK, ${ }^{3}$ Biological Sciences, St. Cloud State University, St. Cloud, MN, USA.

\section{Abstract: (240)}

Silica incorporation into biomaterials, such as Bioglass and Si-substituted calcium phosphate

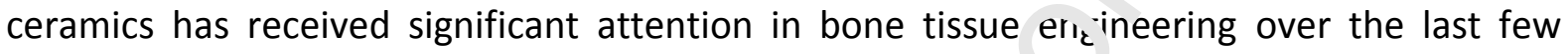
decades. This study aims to explore the dissolution bet. эvio גr of natural biosilica isolated from a freshwater diatom, Cyclotella meneghinian 1, liat has been incorporated into 3D printed poly (DL-lactide -co - glycolide) (PDL : $^{\wedge}$ ) scaftolds using extrusion and additive manufacturing. In the study, two differ... ${ }^{+}$v weight percentage ( 1 wt.\% \& 5 wt.\%) of diatom-silica were incorporated into PDLGA -caffolds that were then degraded in phosphate buffered saline (PBS) cell free medi $₫$. „، addition, pure PDLGA scaffolds and 5 wt.\% Bioglass scaffolds were used as contrn I troups. The degradation study was performed over 26weeks. The release rate $\mathrm{c}^{f} \mathrm{Si}^{\prime}$ ions from diatom-PDLGA scaffolds was found to increase

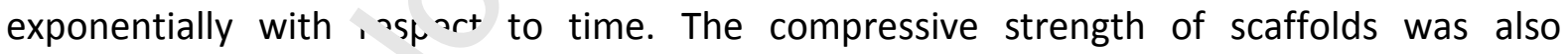
measured with the Diatom-PDLGA scaffolds found to maintain their strength for longer than either pure PDLGA scaffolds or 5 wt.\% Bioglass scaffolds. ${ }^{13} \mathrm{C}$ NMR data showed that diatom biosilica containing scaffolds had less degradation than pure or bioglass-containing scaffolds at comparable time-points. Overall, the Diatom-PDLGA scaffolds were found to have more desirable physiochemical properties for bone repair compared to Bioglass.

Key words: Diatom-silica, PDLGA, additive manufacture, FDM, bone repair. 


\section{Introduction:}

Interest in three-dimensional (3D) printing technologies has developed at a remarkable pace in bone tissue engineering over the past decade. This is due to their ability to produce bone scaffolds with customised-designed shape and tailored porous structures and properties ${ }^{1}$. The need for bone replacement strategies as a result of degenerative bone diseases and fractures has increased significantly due to an increase in oging population and overall population growth ${ }^{2}$. The advances in 3D printing of bon s sciffolds includes fabrication techniques, morphological profile design, material $d \epsilon \epsilon^{\prime}$. $r$.nent, and more recently the ability to print composite materials ${ }^{3,4}$. To proc 'ce optimised porous scaffolds with appropriate properties (e.g. biodegradabilit', k'ocompatibility, and bioactivity), new composite materials are being develor ed tha are suited to 3D printing with bioactive properties to enhance bone replacer. ont $^{5-7}$. However, there are still a number of challenges to overcome using these technologi $s$ that include improved mechanical properties and a reduction in process induced $r$ slyrı. ar degradation ${ }^{7}$.

Fused deposition modt.'ing (FDM) is a common 3D printing technology that uses a layer-bylayer technique to build 3D scaffolds ${ }^{8,9}$. To create the layers, thermoplastic polymers/composites with thermally lowered viscosity are deposited onto a moving platform. In recent years, the ability to print composite materials has made this technology more attractive for bone repair ${ }^{10}$. Recent studies have shown the feasibility of printing polymer filaments that contain hydroxyapatite (HA) and beta tricalcium phosphate ( $\beta$-TCP) that have resulted in improved mechanical and bioactive properties using standard FDM 3D printers $^{11,12}$. Some new FDM 3D printer contain dual nozzle heads or in-nozzle impregnation 
that enable polymers to be blended with fibre or particles during printing ${ }^{6}$. In addition, unlike other solid freeform scaffold fabrication technology, FDM does not require using any solvent, making it a greener approach to scaffold fabrication ${ }^{13}$.

Biodegradable polymers have been used for bone repair since the $1990 \mathrm{~s}^{14}$. They include polymers, such as polylactic acid (PLA), polyglycolic acid (PGA), polyvinyl alcohol (PVA), polycaprolactone $(\mathrm{PCL})^{15-21}$ and more recently poly (DL-lactide-co-glycolide) (PDLGA, or sometimes abbreviated in literature to PLGA) ${ }^{15}$. All of thes? pclymers are suitable for 3D

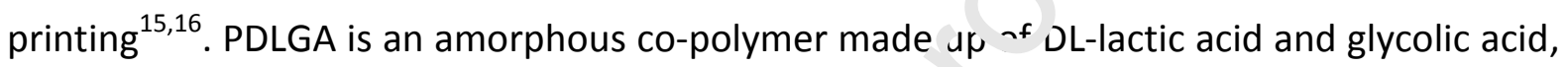
which is non-toxic and approved by Food and Drug, dm nistration (FDA) as a component of a range of medical devices ${ }^{22}$. The ability to $m$ ar k ulate the degradation profile of PDLGA through the modification of the copolv ne isatıon ratio of its monomers offers significant promise in biomedical applications. 2ifferent ratios of these monomers, lactic and glycolic acid $^{23}$ can vary its degradation pru'ile from 1 week (PDLGA 50:50) to 6 weeks (PDLGA $85: 15)^{24}$, making it suitable f.ir applications ranging from drug delivery system to bone scaffolds ${ }^{25-28}$. It is also higı.'v sersatile in terms of fabrication and has been successfully formed into plates, mes' 'es and screws for medical applications ${ }^{24,29}$.

In recent years, silica has attracted more attention in terms of its role in bone repair ${ }^{30-32}$. Over the last 30 years the literature has shown strong evidence that dietary silicon is beneficial to bone health ${ }^{33,34}$, but the exact biological role(s) of silica in bone repair is still not clear either in terms of dietary or implanted silica ${ }^{33}$. Additional evidence to support the therapeutic benefit of silicon in bone is provided by in vivo and in vitro studied with siliconcontaining implants and ceramics, such as Si-substituted hydroxyapatites and Bioglass ${ }^{33,35,36}$. 
Silicon-containing bone fillers and scaffolds have been reported to bond more effectively to bone compared to non-silicon-containing implants. This has been attributed to the spontaneous formation of a biologically active apatite-like layer on their surface ${ }^{37}$. Silicon has also been shown to be involved in gene upregulation, osteoblast proliferation and differentiation, type I collagen synthesis and apatite formation. For example, a study from Mieszawska et al., found the presence of silica upregulated the gene expression in osteogenesis ${ }^{38}$. One recent paper reported more ordered co 'agen fibrils and mature bone formation with Si-substituted hydroxyapatite granular impli $\mathrm{nts}^{-{ }^{9}}$. The function of silicon in bone regeneration has not been clearly established. Th e ${ }^{n}$ r.centration of $\mathrm{Si}$ in bone tissue has been reported to be in the range of $100-15 \mathrm{pr} \mathrm{m}$ in bone and $200-600 \mathrm{ppm}$ in cartilage/connective tissues ${ }^{36,40}$.

Bioglass $45 \mathrm{~S} 5$, which contains $45 \mathrm{wt} .2 / 1 \mathrm{SiO}_{2}$, has shown promise in bone tissue engineering. The major advantages of Bioglass is i's ',one-bonding capability, therapeutic ion release and enhanced cell growth and $d$ ffer ntiation ${ }^{41,42}$. However, its incorporation into polymer scaffolds, has resulted in lo:'e' mechanical strength and poorer fracture toughness ${ }^{43,44}$. In recent years, diatom $t_{1}$ : stule (i.e. cell walls) has received some positive interested in bone tissue engineering, mostly because of its chemical composition and unique morphological structure. Thi et al., ${ }^{45}$ demonstrated that diatom biosilica can undergo dissolution in aqueous environments to release silicon ions. They also reported that diatom biosilica particles have little or no cytotoxic effect in vitro study using embryonic Swiss mouse fibroblast cells (3T3). This was supported by Walsh et al., who reported that diatom biosilica was non-cytotoxic to $\mathbf{J 7 7 4 . 2}$ macrophage cells in vitro, and supports cell proliferation and growth of hBMSCs ${ }^{46}$. 
This study investigates the effect of natural biosilica (freshwater diatom, Cyclotella meneghiniana) compared to synthetic silica (Bioglass ${ }^{\oplus} 4555$ ) in FDM 3D printed PDLGA polymer scaffolds; in terms of their degradation profile and mechanical properties to assess their potential in bone repair applications. The FDM 3D printed scaffolds were fabricated using the method described by Little et al., ${ }^{7}$ with slight modification to processing conditions to accommodate the addition of the different biocerami filler. This study aimed to understand the degradation rate of the scaffolds in terms o: pol mer degradation and silica release. In addition, the compressive strength of the sinf.olds was measured over the duration of the study. The study was perforrı. 'd Jver 26-week in PBS. Molecular characterisation of the hydrolytic degrad ttior of PDLGA was studied using 13 


\section{Materials and Methods:}

\subsection{Materials}

\subsubsection{Biosilica Bone Filler - Diatoms and Bioglass}

C. meneginiana diatoms were collected from the Mississippi River, USA, isolated and cultured as previously described by Walsh et al., ${ }^{46}$. A nitric $\bar{a}^{-i d}\left(\mathrm{HNO}_{3}\right)$ digest was used to partially remove the organic fraction by Prof. Julius group. T ie $r$ sultant samples were then freeze dried and sealed in a vacuum-packed bag for tr.ins, n , t to the UK. On receipt of the samples the diatoms were washed repeatedly $\left(\lambda_{.}\right.$.) vith $1000 \mathrm{~mL}$ of deionised (DI) to neutralise the residual acid. Thereafter, the di tr $r$ samples were heat in an Elite chamber furnace (BMF 11/7) at $550{ }^{\circ} \mathrm{C}$ for $1 \mathrm{~h}$,ur to ımove the remaining organic matter. The resultant diatom sample was assignt + the name "heat treated (HT) diatom" in subsequent studies. Bioglass $45 \mathrm{S5}$ (Sylc ${ }^{\mathrm{TM}}$. Ferearch Ltd, London, UK) from Denfotex (EJR, D095325/K062502, Reg. No. $\left.\varepsilon^{\prime} 2.6 \mathrm{c} 30\right)$ of mean particle size of 5 to $80 \mu \mathrm{m}$ was also used in this study. Prior to use the Diri'ied diatom biosilica and Bioglass $45 \mathrm{~S} 5$ were vacuum dried at $40^{\circ} \mathrm{C}$ under 10 mbar of $\uparrow$-essure for 2 days before they were blended with PDLGA.

\subsubsection{Poly (DL-lactide-co-glycolide) (PDLGA) Polymer}

Medical grade PDLGA (85:15) polymer granules (Boehringer Ingelheim Resomer RG 859 SR) were stored in the fridge $\left(-4^{\circ} \mathrm{C}\right)$ in a sealed bag to prevent the degradation of polymer. Prior to use, PDLGA polymer was brought to room temperature overnight. It was then opened and dried under the same conditions as the bioceramic fillers (described above) before being blended together. 


\subsubsection{Phosphate Buffered Saline (PBS) Buffer}

PBS was selected at $\mathrm{pH} 7.4$ to mimic the normal $\mathrm{pH}$ environment in human body ${ }^{47}$. The main characteristic from PBS buffer is stability for a long term study ${ }^{48}$, hence being recommended as the in vitro soaking solution in BS ISO 13781:2017; Implants for surgery Homopolymers, copolymers and blends on poly(lactide) - In vitro degradation testing. The PBS was prepared by adding $0.19 \mathrm{~g}$ of potassium chloride $(\mathrm{KCl})$ with $0.20 \mathrm{~g}$ of monopotassium phosphate $\left(\mathrm{KH}_{2} \mathrm{PO}_{4}\right), 8.06 \mathrm{~g}$ of sodium chloric $(\mathrm{NaCl})$ and $1.14 \mathrm{~g}$ disodium phosphate $\left(\mathrm{Na}_{2} \mathrm{HPO}_{4}\right)$ to $\approx 800 \mathrm{~mL}$ deionised water. The $\wedge^{4}$ was adjusted to 7.4 using hydrochloric acid $(\mathrm{HCl})$. The solution was mixed then $\mathrm{tc}$, vea up to a final volume of $1000 \mathrm{~mL}$ in a volumetric flask. The PBS was left overnight to $c_{1}--k$ the stability of the $\mathrm{pH}$ before use in degradation study.

\subsection{Methods}

\subsubsection{Blend Preparation and I ila. .ent Fabrication}

PDLGA polymer and biosilica bu.ne filler (diatom biosilica and bioglass 45S5) were mixed homogeneously by hane aft $r$ vacuum drying for individual components for two days. After blending, each prepared 'lend was dried for a further 1 day in vacuum oven under the same conditions before the filaments were extruded. The four filament groups extruded included: Pure PDLGA filament (Control), 1 wt.\% Diatom-PDLGA filament, 5 wt.\% Diatom-PDLGA filament and 5 wt.\% Bioglass-PDLGA filament. This is similar concentrations used in previous studies that was reported to show better mechanical properties when compared to higher concentrations of 10 and $20 \%{ }^{49,50}$. In addition, small concentrations (typically up to $1.5 \%$ ) of silica have been reported to induce a therapeutic response in response in bone ${ }^{51}$. A Haake 
twin-screw extruder (Thermo Fisher Scientific, Germany) was used to produce filaments. The extrusion temperature varied between $165{ }^{\circ} \mathrm{C}$ to $175{ }^{\circ} \mathrm{C}$ at different stages of the extrusion process. All filaments were fabricated to a diameter of $1.75 \mathrm{~mm}$ which was required for the FDM 3D printer.

\subsubsection{D Printing Bone Scaffolds via Fused Deposition Modelling (FDM)}

A RepRap Mendel (RepRapPro, UK) 3D printer was used to fal ricate the bone scaffolds with a method similar to the one described by Little et al., ${ }^{7}$. A s. and ird architecture of scaffold was selected and designed using SolidWorks 2010, and thin converted from STL to G-Code using opensource Slic3r 1.2.9. Printrun (or Printerín-e) joftware was connected to the 3D printer to control the movement and amount ( $f$ ',$c^{\prime} y m e r$ filament extruded from the nozzle head $(\varnothing 0.4 \mathrm{~mm}$ ) using G-Code. The pr iting temperatures and parameters used are summarised in Table 1. The pure ?DLGA scaffolds were printed at $190^{\circ} \mathrm{C}$, which was comparable with the previous stıay b/ Little et al. ${ }^{7}$, After the incorporation of diatom or bioglass 45S5, a trial and err - approach was taken between 160 to $245^{\circ} \mathrm{C}$. The optimum print temperature was dn+e, $\sim$.ned according to scaffold size, shape and porous structure after printing, and ea. $\mathrm{V}$ of extrusion from print nozzle. In addition, the platform temperature on 3D printer was maintained at $60{ }^{\circ} \mathrm{C}$ throughout the print process. The scaffold was built up by 24 layers switching between printing in horizontal and vertical direction. For example, the polymer strips in the first bottom layer were printed along the $X$ axis, and the second layer from bottom was printed along the $Y$ axis. This cycle was repeated for 12 times to build up the scaffold. There was approximately $150 \mathrm{~mm}$ of filament used for each scaffold. 
Table 1: FDM Parameters

\begin{tabular}{|l|c|}
\hline \multicolumn{1}{|c|}{ Parameters } & Values \\
\hline Print Temperatures: & $190^{\circ} \mathrm{C}$ \\
\hline Pure PDLGA Scaffold & $220^{\circ} \mathrm{C}$ \\
\hline 1 wt.\% Diatom-PDLGA Scaffold & $225^{\circ} \mathrm{C}$ \\
\hline 5 wt.\% Diatom-PDLGA Scaffold & $165^{\circ} \mathrm{C}$ \\
\hline 5 wt.\% Bioglass-PDLGA Scaffold & $100 \mathrm{rpm}$ \\
\hline Print Details: & $22 \mathrm{~m} \mathrm{n}^{\prime} \mathrm{s}$ \\
\hline Fan Speed & $130 \mathrm{~mm} /-$ \\
\hline Print Speed & 0.2 \\
\hline Travel Speed & $\mathrm{mn}$ \\
\hline Layer height
\end{tabular}

\subsubsection{Morphology Study on diatoms}

To investigate the morphology of the C. Mer.eghı,iana diatoms, scanning electron microscopy (SEM), atomic force microscony 'AFIVI), and transmission electron microscope (TEM) were used on HT diatoms. A FEI $Q_{\iota}$ ?nta FEG - Environmental SEM from Oxford EXACT was used to image the diatoms i $>r$ lınaging, a few frustules were spread on the carbon tab, which was attached on thc SEN, specimen stub. The SEM sample was then coated by AGAR Gold Sputter Coater for 10 seconds under an argon environment prior to imaging in the SEM. For the AFM, эn ( xford Instrument Cypher ES Environment AFM was used. The sample was prepared $\because$, suspending a small number of diatom frustules in acetone in a microcentrifuge tube. Afterwards, the mixture was shaken by Grant Instruments ${ }^{\mathrm{TM}} \mathrm{PV}-1$ personal vortex mixer for a few minutes to disperse the diatom frustules into single particles. A dropper was then used to transfer the diatom suspension directly on to the AFM specimen disc. The acetone was left to evaporate off prior to imaging. The preparation of TEM sample was similar to the AFM. HT diatoms were spread on a TEM copper grid instead 
of AFM specimen disc. The TEM used was a TF20D Tecnai transmission electron microscope manufactured by Philips.

\subsubsection{Micro-Computed Tomography on scaffolds}

Micro-CT was used to image the 3D structure of the scaffolds. The micro-CT scanner used in this study was a $\mu \mathrm{CT} 40$ from Scanco Medical with a sealed $\mathrm{x}-$ - -7y source $(30 \mathrm{kVp}-70 \mathrm{kVp})$. The printed scaffold was placed in the sample holder and In $\left.\operatorname{li}_{i}\right\lrcorner$ in the machine to start the scanning process which took approximately one hour $\mathrm{u}_{1}$, ter $70 \mathrm{kVp}$.

\subsubsection{The Degradation Study on $\subseteq$-affolds}

For the long-term degradation stיidy ir vitro, each scaffold was immersed in $15 \mathrm{~mL}$ of PBS (method see 2.1.3) in a $15 \mathrm{~mL}$ metal free Falcon tube for 26 weeks. The timeframe of this study was selected baser $n n_{,}$; evious literature on P(CL-Co-LA)-PEG-P(CL-co-LA) scaffolds ${ }^{52}$. A PBS control without $a_{1}$.' scaffolds was included to assess the stability of the buffer. In this study one scaffold per group (x3 additional replicates) was added to each tube. At set timepoints, the PBS solution was removed and refreshed with new PBS. In addition, during the study, the PBS solution was refreshed every two weeks for all samples. The spent PBS solution was tested using ICP-OES and the cumulative Si ion release was calculated for each timepoint. There were four replicated samples at each time point to calculate the average change in $\mathrm{pH}$ and released silica with respect to time. The samples were incubated in a 
Stuart shaking incubator SI500 oven at $37^{\circ} \mathrm{C}$ and were agitated at $70 \mathrm{RPM}$ throughout the degradation study.

\subsection{Characterisation}

\subsection{1 pH Change in Dissolution and Degradation Study}

A Jenway $3510 \mathrm{pH}$ metre was calibrated by reference buffe is $(1 \mathrm{H} 4, \mathrm{pH} 7 \mathrm{pH} 10)$ before recording the $\mathrm{pH}$ change from $\mathrm{PBS}$ during the degradat in ,tudy. The $\mathrm{pH}$ value from the degradation study was recorded after the sampl $\leqslant s w$ re removed from oven and then cooled down to $20^{\circ} \mathrm{C}$ to ensure the accuracy of $\mathrm{nr}$ - measurement.

\subsubsection{Inductively Coupled Plasma - Ł.tical Emission Spectrometry (ICP-OES) Analysis}

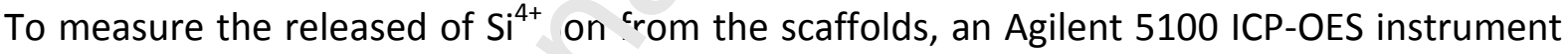
was used. Prior to analysis, t'e instrument was flushed with a $2 \%$ nitric acid $\left(\mathrm{HNO}_{3}\right)$ rinse solution and then calik ate I with a bulk mixed element solution that was applied with different concentratior (r.1ppm, 1ppm \& 10ppm). Each sample was tested in triplet. The $2 \%$ $\mathrm{HNO}_{3}$ rinse solution was also used at periodic intervals during analysis to ensure the accuracy. Additional information on the ICP-OES method are given in the supplementary information.

\subsubsection{The Compressive Strength of Scaffolds}


A Zwick/Roell Z100 instrument was used to test the compressive strength of scaffolds in the degradation study at the different timepoints. Samples were tested at weeks 1,4 and 8 . Beyond week 8 the samples became too fragile to handle. Prior to compression testing, the scaffolds were collected from the PBS solution using tweezers and wiped with a dry tissue to remove excess moisture. In addition, the original scaffolds (week 0), before the degradation study, were also tested as the control sample. All scaffolds were compressed to 0.5 strain with a strain rate of $2 \mathrm{~mm} / \mathrm{min}$, which means the scaffolds $\mathrm{u}$ are forced to the half original height at the end of test. The preload was set to $150 \mathrm{~N}$ on i he s affolds with the exception

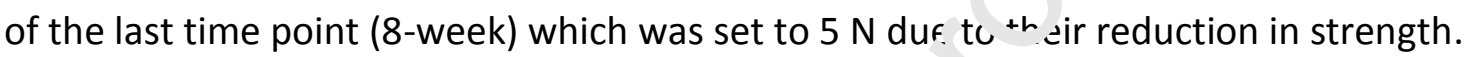

\subsubsection{Degradation Analysis on Scaffolds via ${ }^{3}$ - MR Spectroscopy}

${ }^{13} \mathrm{C}$ NMR was performed on the crushea $\because$ affolds at the following timepoints: $0,1,4$, and 8 weeks. Samples were also taken at waen-12 and 16 which were too fragile to mechanically test but were suitable for NM'r a.?alysis. For each NMR spectra $40 \mathrm{mg}$ of the scaffold powder was dissolved in 0.7 n... of deuterated chloroform $\left(\mathrm{CDCl}_{3}\right)$ for 2 hours at room temperature $\left(\approx 20{ }^{\circ} \mathrm{C}\right)$ ( sins the method described by Petisco-Ferrero et al. ${ }^{53}$. The mixed solution was then analısf d on a Bruker DPX400 NMR spectrometer.

\subsubsection{Statistics Analysis}

IBM SPSS version 25.0 was applied for the statistical analysis of variance (ANOVA) between different groups and factors in this study. Two-way ANOVA was performed on the silicon release and compressive strength data for the scaffolds. Tukey post-doc test was used for all statistical comparisons. 


\section{Results and Discussion:}

\subsection{Diatoms and scaffolds}

The morphology of HT diatoms was studied with AFM, SEM and TEM. Fig. 1a shows the AFM images of a unicell diatom, which is approximately 8 to $10 \mu \mathrm{m}$ in diameter. This result is in agreement with the average size of $C$. Meneghiniana diatom $(6-18 \mu \mathrm{m})$ from previous studies $^{54-56}$. Both the AFM (Fig 1a) and SEM (Fig 1b) images show the elaborate patterns of perforations corrugate, and uniform waves are visible on the suı ' 7 ce of diatom. A side view of a single diatom is shown in Fig. $1 \mathrm{~b}$ from SEM. It is eas $u$ ovserve the girdle band, which holds the two overlapping diatom valves together. Snme tiny pores are also visible from the top valve with an undulating radial pattern. In adritic: marginal spines are found at the edge of underside valve on the left side of the SLivl image. Fig. 1c displays a fragment from diatom under TEM. Nano-holes ( 50 nni, are visible in a uniform pattern along the surface of the frustule. These nano-holes car roı, ${ }^{\text {trol }}$ the diatom access to the external environment for processes such as waste rem svai and mucilage secretion ${ }^{45}$.The darker region on the TEM (Fig 1c) indicate a denser $n_{1}$. tt. ial, which could be a thicker section of biosilica. Fig. 2 presents the 3D image of , template PDLGA scaffold after printing from micro-CT. The scaffold is an upright $v^{\prime}$.nder built up layer by layer with some regular porous structure inside. The average scaffold diameter was $12.5( \pm 0.2) \mathrm{mm}$, with a height of $6.0( \pm 0.1) \mathrm{mm}$. Each scaffold was found to be approximately $0.44( \pm 0.02) \mathrm{g}$, and the width of the strut in the ranged of 0.34 to $0.42 \mathrm{~mm}$. In terms of the porous structure, the ratio of the relative solid volume was found to be 0.35 , which means the scaffold has more than half of its total volume taken up by porous space. Supplementary data (Fig. 1) shows the microstructure of 
each scaffold type and indicative example of strut width. The distribution of the bioceramic

filler within the composites materials is also shown in (Supplementary data, Fig. 2).

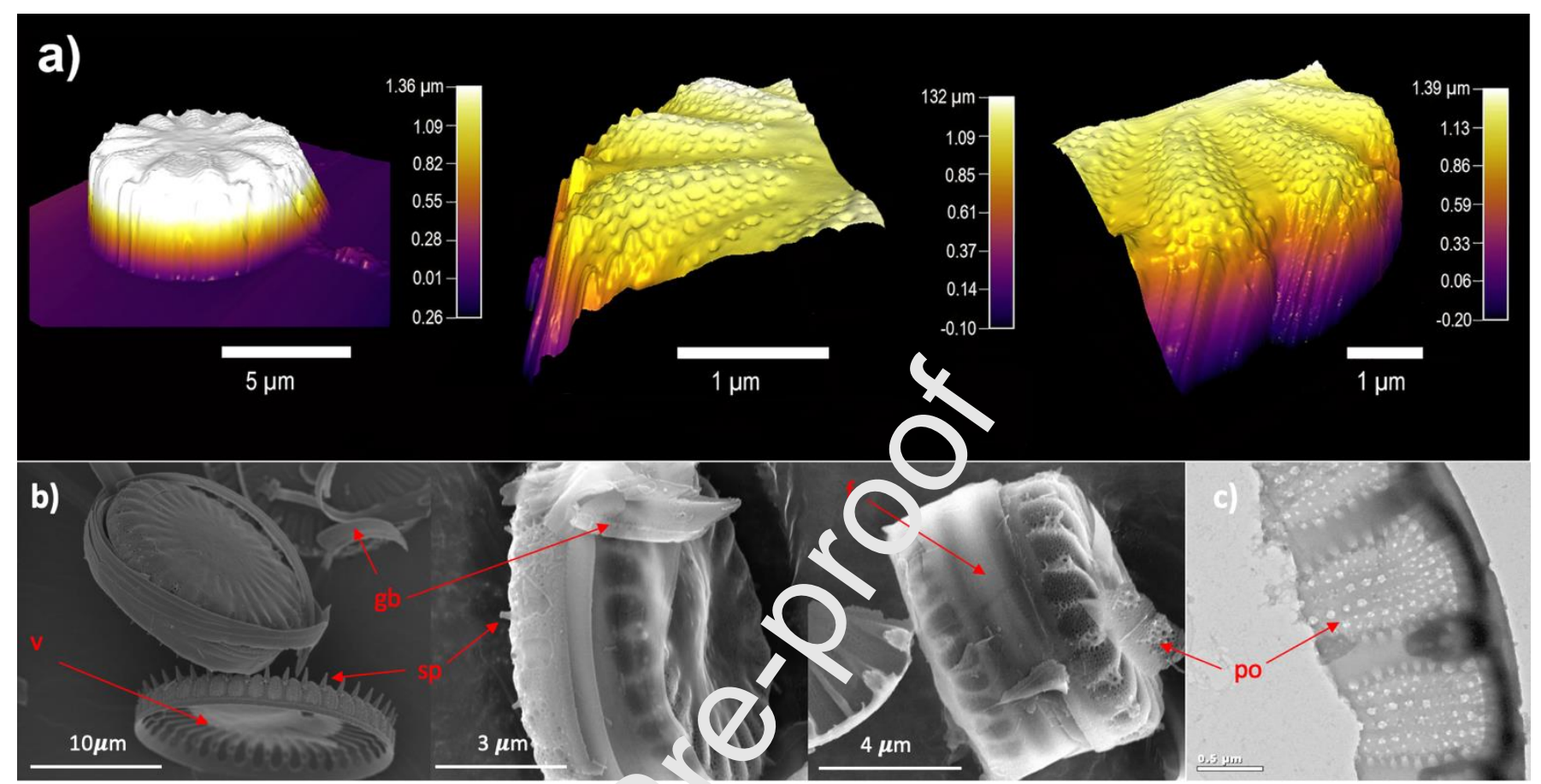

Fig. 1. (a) AFM images of diatoms, (b) SEM imas \& of diatom biosilica frustules and valves, and (c) The fragment of diatom from TEM. Abbreviation. of diatom features: (po) pore openings, (sp) spines, (gb) gridle band, (v) valve, (f) intact diatom frustule

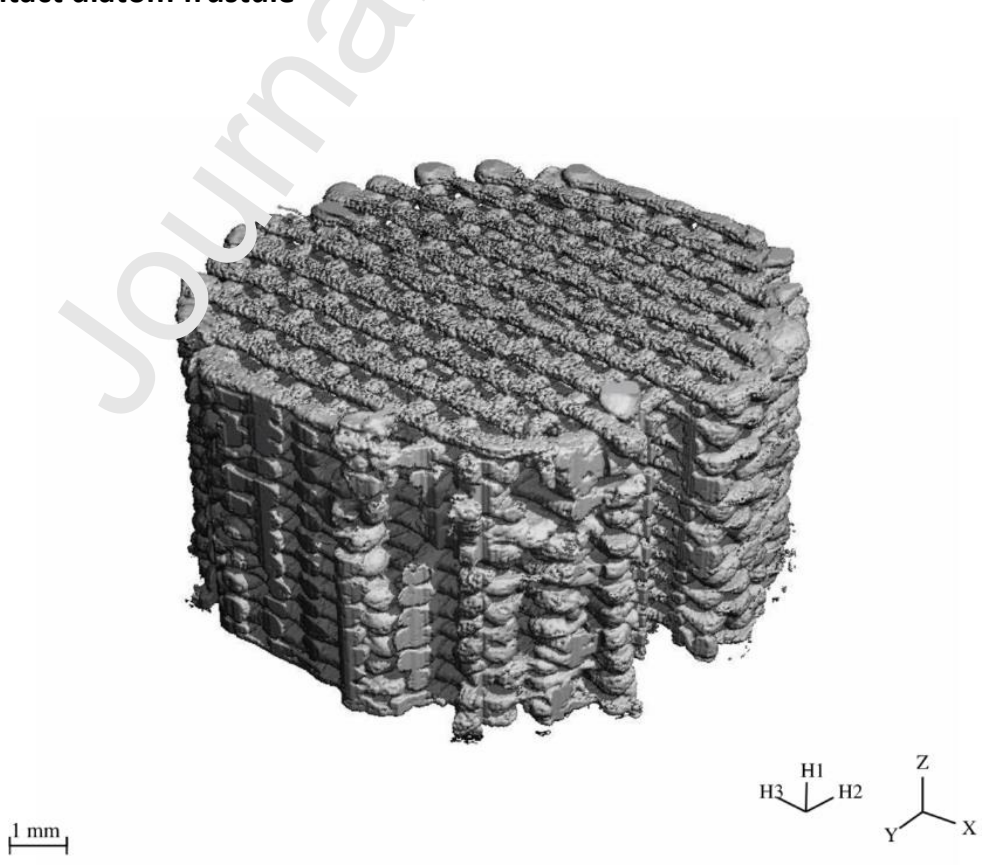

Figure 2: Typical 3D printed scaffold from micro-CT 


\subsection{Degradation Study on Scaffolds}

After 3D printing, a 26-week degradation study was performed on scaffolds. At each timepoint images were taken to visibly map their changes, shown in Table 2. Both 1 wt.\% and 5 wt.\% diatom-PDLGA scaffolds maintained their shapes and porous structure within the first 8 weeks. However, the shape of the pure PDLGA scaffolds and 5 wt.\% BioglassPDLGA scaffolds became slightly distorted after 2-weeks and were tacky to the touch. After 10 weeks, the structure of pure PDLGA scaffold broke down ompletely, turning it into a viscous substance at the bottom of the tube. The $5 \mathrm{wt} \%$ bing'dss-PDLGA scaffold kept its general shape but became very swollen and distortec hetore also breaking down at week 10. However, the diatom scaffold groups (1 wt.\% anı' 5 wt.\%) showed no obvious swelling and maintained their shape up to week 12 . Atfi two more weeks, all scaffold groups degraded into a viscous substance. At : re nd of the experiment in week 26, there was no polymer left in the pure PDLGA sca ${ }^{\text {ffold }}$ and 5 wt.\% Bioglass-PDLGA scaffold groups. However, both diatom-PDLGA sc-'ffol' oroups had some polymer residue.

Previous studies of $P \cap L C(4 \mathrm{w}$ th a ratio of 85:15 lactic acid to glycolic acid reported complete degradation occurred ' etween 12 to 16 weeks. Agrawal et al., ${ }^{57}$ reported a similar degradation period of 12 weeks in vivo that implanted PDLGA cylinder subcutaneously into the back of the male adult Wistar rats ${ }^{58}$. Wu et al., reported a slightly longer degradation period of 16 weeks for pure PDLGA (85:15) scaffolds that were fabricated using a compression moulded/particulate leach technique in an cell free in vitro degradation study that was performed in PBS ( $\mathrm{pH}$ 7.4) buffer solution ${ }^{59}$. A detailed study on the hydrolytic degradation of PDLGA with different molecular weights and ratios of lactic to glycolic acid by 
Robles-Bykbaev et al., found that degradation was strongly linked to carboxylic group formation, although the $85: 15$ ratio was not included in their study ${ }^{22}$. Other factors also influencing the degradation processes included the increase in chemical interactions between the hydrolytic groups, the scaffolds specific surface area ${ }^{26}$ and the molecular weight of PDLGA $(85: 15)^{60}$. The addition of ceramic material has also been found to influence the degradation of PDLGA. A study by Ara et al, found the addition of calcium carbonate and calcium phosphate to PDLGA decreased the $r_{c}{ }^{\text {te }}$ of degradation of PDLGA ${ }^{61}$. A similar finding was observed in our study whereby both di łtom-PDLGA and BioglassPDLGA scaffolds took longer to degrade (Table 2). 
Table 2: Images of the scaffolds in PBS buffer solution during the 26-degradation study.

\begin{tabular}{|c|c|c|c|c|}
\hline Duration & $\begin{array}{c}\text { Pure PDLGA } \\
\text { Scaffold }\end{array}$ & $\begin{array}{l}1 \text { wt.\% Diatom- } \\
\text { PDLGA Scaffold }\end{array}$ & $\begin{array}{l}5 \text { wt.\% Diatom- } \\
\text { PDLGA Scaffold }\end{array}$ & $\begin{array}{l}5 \text { wt.\% Bioglass - } \\
\text { PDLGA Scaffold }\end{array}$ \\
\hline 2 Weeks & & & & \\
\hline 8 Weeks & & & & \\
\hline 10 Weeks & & & & \\
\hline 12 Weeks & & & & \\
\hline 14 Weeks & & & & \\
\hline 16 Weeks & & & & \\
\hline 20 Weeks & & & & \\
\hline 26 Weeks & & & & \\
\hline
\end{tabular}


Fig. 3 shows the $\mathrm{pH}$ change during the degradation study. The results found that the control sample (PBS buffer without scaffold) was found to stay stable at $\mathrm{pH} 7.4$ throughout the experiment with little fluctuation. The results from the pure PDLGA scaffold group displayed a significant pH drop at week 8 and 14 to $7.09( \pm 0.12)$ and $2.35( \pm 0.12)$ respectively (Fig. 3a), and then recovered to 7.4 in week 24 due to the refreshment of PBS solution every two weeks. The acidic lowering of $\mathrm{pH}$ is a result of the degradation of the by-products of lactic acid and glycolide acid. This drop in $\mathrm{pH}$ value is comparab. 0 to those reported in other studies during PDLGA degradation ${ }^{62,63}$. Farahani et al., repor ed hat the $\mathrm{pH}$ drop was partly related to the release of the lactic acid groups into th $₫ ル \sim$ environment ${ }^{64}$. Both diatomPDLGA scaffold groups displayed a similar pH chang wit । respect to time (Fig. $3 b$ \& $3 c$ ). The significant $\mathrm{pH}$ change started at week 10 , as o ip us əd to week 8 like pure PDLGA scaffolds. After week 10, the pH level of PBS solut. on trouped to $2.32( \pm 0.02)$ and $2.36( \pm 0.01)$ from $1 \mathrm{wt} . \%$ and $5 \mathrm{wt} . \%$ diatom-PDLGA scu ffold respectively, until week 18 , before recovering to $\mathrm{pH} 7$ in week 24. The lowest $\mathrm{pH}$ re orded from diatom-PDLGA scaffolds was similar with pure PDLGA scaffold, which $m$ : ans diatom biosilica did not affect $\mathrm{pH}$ environment itself. The acidic condition was caused $:$ ine degradation of PDLGA polymer to lactic acid and glycolic acid. However, the ada in of diatoms to PDLGA appears to delay the acid burst release by two weeks, suggesting that the addition of the ceramic played a role in inhibiting degradation. This supports findings by Ara et al, as discussed earlier ${ }^{61} .5$ wt.\% BioglassPDLGA scaffolds, however, turned slightly alkaline increasing in $\mathrm{pH}$ to $8.84( \pm 0.69)$ in the first two weeks. Previous dissolution studies of $45 \mathrm{~S} 5$ bioglass have shown similar trends, and have been reported to increase to a $\mathrm{pH}$ between 8.7 or 9.7 in the aqueous solutions ${ }^{65}$. It is most likely that a reaction is started due to the ionic exchange between $\mathrm{Ca}^{2+} \& \mathrm{Na}^{+}$ions from Bioglass with the $\mathrm{H}^{+}$and $\mathrm{H}_{3} \mathrm{O}^{+}$ions from the PBS solution, which causes an increase in 
$\mathrm{pH}$. Fiume et al, study also reported the release of soluble silica from $45 \mathrm{~S} 5$ Bioglass to form of silanol bonds ( $\mathrm{Si}-\mathrm{OH})$ that increase the $\mathrm{pH}$ of solution. ${ }^{66}$
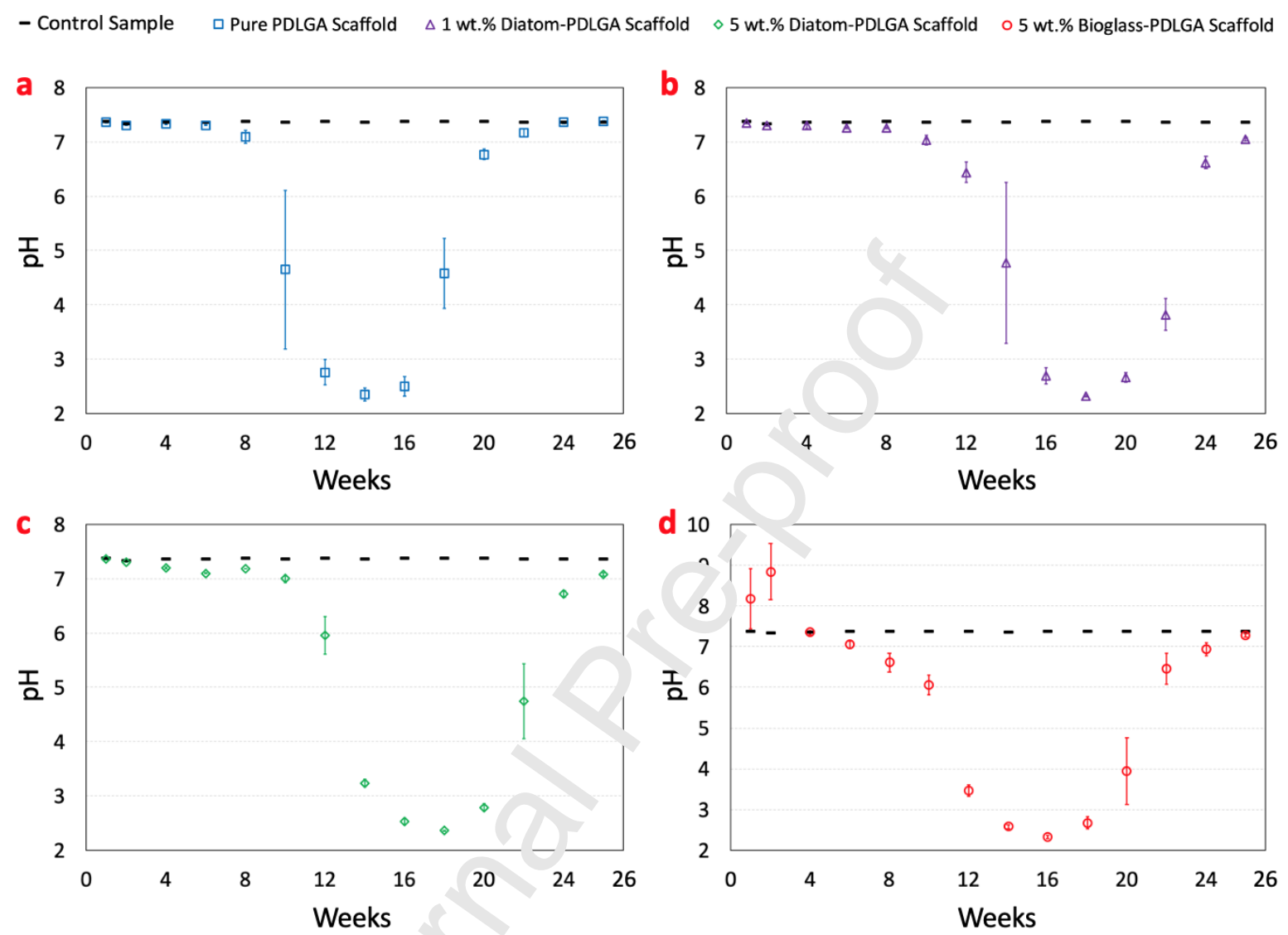

Fig. 1. The $\mathrm{pH}$ changes from 3D p int $\mathrm{d}$ scaffolds in the degradation study (a) Pure PDLGA Scaffolds, (b) $1 \mathrm{wt} . \%$ Diatom-PDLGA Scaffolds, (c) , wı \% Diatom-PDLGA Scaffolds, (d) 5 wt.\% Diatom-PDLGA Scaffolds ( $n=4)$

The cumulative ICP data for Si ions over the 26-week degradation study is shown in Fig. 4. The PDLGA scaffolds with 5 wt.\% Bioglass exhibited the fastest initial release of Si ions in comparison to both diatom-PDLGA scaffolds. After one week, approximately $28.88( \pm 17.36)$ ppm Si ions were released into the PBS solution from 5 wt.\% Bioglass-PDLGA scaffolds. At week 2 the burst release continues, releasing approximately $100.30( \pm 35.87)$ ppm of Si ions into the PBS solution. Thereafter, the release rate of silica was found to slowly increase 
linearly up to $169.43( \pm 14.73)$ ppm in week 20 and $225.94( \pm 5.70)$ ppm in week 26, where $p>0.5$. This is accounted for by the likelihood of some bioglass particles being exposed at the surface of the scaffold, so dissolving in the first two weeks, as a burst release, with later release being from bioglass particles that are entrapped within the polymer.

The 5 wt.\% diatom-PDLGA scaffold group displayed an increasing rate of $\mathrm{Si}$ ion release during the degradation study with no initial burst release, suggesting that the majority of the diatom particles were contained within the polymer rathe! than exposed at the surface. The concentration released was found to be significantlv lunr,r compared to the $5 \mathrm{wt} . \%$ Bioglass-PDLGA scaffolds, until week 24 when a signi icant $(p=0.19)$ increase in Si ions release occurred from $94.19( \pm 9.73) \mathrm{ppm}$ in week $\iota_{\text {: }}$ เo $199.84( \pm 8.77) \mathrm{ppm}$. In the first week, only $0.58( \pm 0.02)$ ppm Si ions were relna: $₫$ d nto the PBS solution. However, week 26 recorded a 272.17 ( \pm 10.94$) \mathrm{ppm}$ level o, $\mathrm{Si}$ ons, which was the highest concentration of ions released between the silica scaffold grc ' $\mathrm{Ds}$. The $1 \mathrm{wt} . \%$ diatom-PDLGA scaffolds displayed a similar increasing rate of Si ions 1 leuse to that of $5 \mathrm{wt. \%}$ diatom-PDLGA scaffold groups, however, at a lower concentrali n. The maximum release of $\mathrm{Si}$ ions in this group was found to be $69.88( \pm 2.22) \mathrm{pr} m$ 't the end of degradation study. Both diatom-PDLGA scaffold groups have an initial slo ver steady release rate of Si ions compared to the Bioglass-PDLGA scaffold groups, with a later near-exponential increase. These differing temporal characteristics in release rate may relate to the differing solubility of bioglass when compared to diatoms (e.g. pH) and/or different physical characteristics, such as specific surface area (SSA), crystallinity and particle size. Previous studies have reported on the significant $\mathrm{pH}$ increase in bioglass after initial immersion into PBS solution due to the ion exchange between $\mathrm{Na}^{+}$and $\mathrm{Ca}^{2+}$ ions in the glass and the $\mathrm{H}^{+}$protons in the PBS, which accordingly increases the ionic concentration of the solution ${ }^{67,68}$. It is likely that this spike in 
$\mathrm{pH}$, which is also evident in our results (Fig 3d) contributed to accelerating the degradation/hydrolysis of PDLGA as the buffer solution turned alkaline at a pH just below 9. Polymer degradation is known to accelerate in both alkaline and strong acids conditions ${ }^{69}$. In terms of the physical properties of the fillers, Walsh et al., ${ }^{41}$ reported the SSA of $C$. meneghiniana to be $\sim 33.67 \mathrm{~m}^{2} \mathrm{~g}^{-1}$ whereas Bioglass $45 \mathrm{~S} 5$ has been reported to be significantly lower in the range of 0.15 to $2.7 \mathrm{~m}^{2} \mathrm{~g}^{-1} 70$. In theory the higher SSA should dissolve faster, however, the fillers are not directly expose ${ }^{i}$ to the buffer solution, they have been blended with polymers, then melted and fcrme 1 into polymer filaments. Therefore, the higher SSA may have resulted in a bet.e, h',nd between the polymer and ceramic phase between the diatoms and PDLGA 1 , sult ng in a slower release rate in the diatom filaments. The desired silica release p of ic to induce a therapeutic effect in bone still largely unknown in the literature. A ev I w siudy by Khandmaa et al. concluded that the release of $16-20$ ppm Si ions frorı. biomaterials could stimulate bone repair ${ }^{71}$. This was supported by a study by Ruangsuriya et al. who found that a concentration of $500 \mu \mathrm{M}(\approx 14$ ppm) of Si ions could increas the gene expression associated with osteocalcin activity ${ }^{72}$. Pingping et al. $^{73}$ study alsn s hr wed that low concentrations of Si ions of $0.625 \mathrm{mM}(\approx 17.5$ ppm) could significan ¿: enhance the proliferation, mineralisation, bone-related gene expression and bone matrix proteins of bone marrow stromal cells (BMSCs). Silicon in bone has been reported in the range of 100 to $150 \mathrm{ppm}$ and $200-550 \mathrm{ppm}$ in extracellular bone $e^{36,74,75}$. 


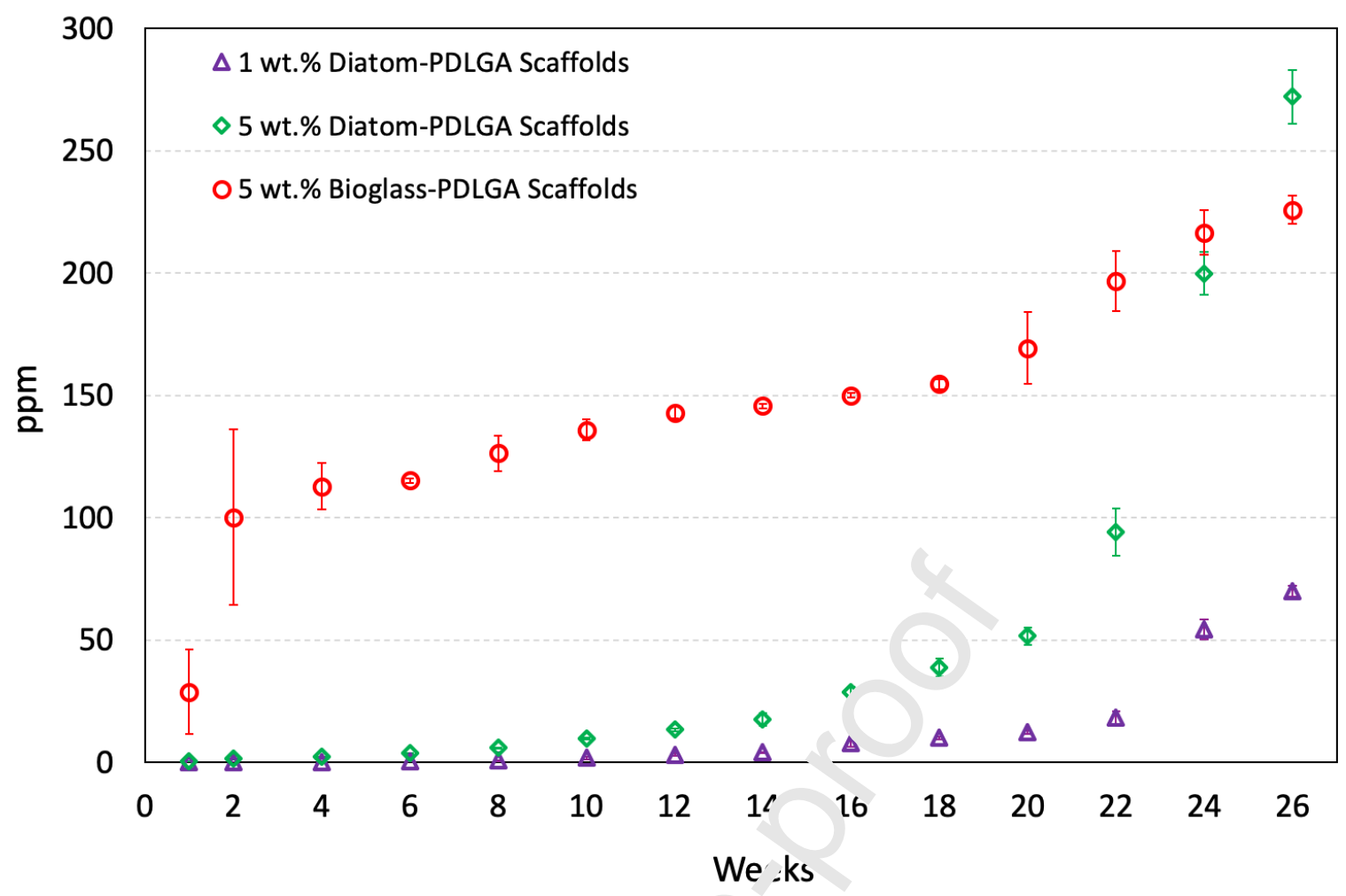

Fig. 2. The accumulated silica release from 3D pr nte $\sim$ - caffolds during the degradation study $(n=4)$

\subsection{Compression Test on Scaffolds}

The mechanical properties we e sildied under compression testing that was performed on the scaffolds at the earlier timt points. Typical stress-strain curves from week $0,1,4$ and 8 are shown in Fig. 5. $\mathrm{N}^{+}$e _ dffolds could not be tested for the duration of the study, as they became too difficult to handle. Fig. 5a shows a typical stress-strain curves of the original scaffolds prior to immersion into PBS buffer solution. The pure PDLGA scaffold (blue line) exhibited the largest yield stress, just over $20 \mathrm{MPa}$, with a Young's modulus of $470 \mathrm{MPa} .5$ wt.\% Bioglass-PDLGA scaffold (red line) had slightly lower mechanical properties with a yield stress of $18 \mathrm{MPa}$, compressive stress of $43 \mathrm{MPa}$ and a Young's modulus of $435 \mathrm{MPa}$. Both diatom-PDLGA scaffolds (1 wt.\% - purple line and 5 wt.\% - green line) exhibited a similar yield stress of $12 \mathrm{MPa}$ and compressive stress of between $30-33 \mathrm{MPa}$. The Young's 
modulus was found to be significantly higher at $260 \mathrm{MPa}$ in 5 wt.\% diatom-PDLGA, compared to 1 wt.\% diatom-PDLGA scaffold was found to be $190 \mathrm{MPa}$. Compared with the reference value of natural cancellous bone $(2 \text { to } 45 \mathrm{MPa})^{76,77}$, the compressive strength from the original scaffolds could meet the requirement for cancellous bone.
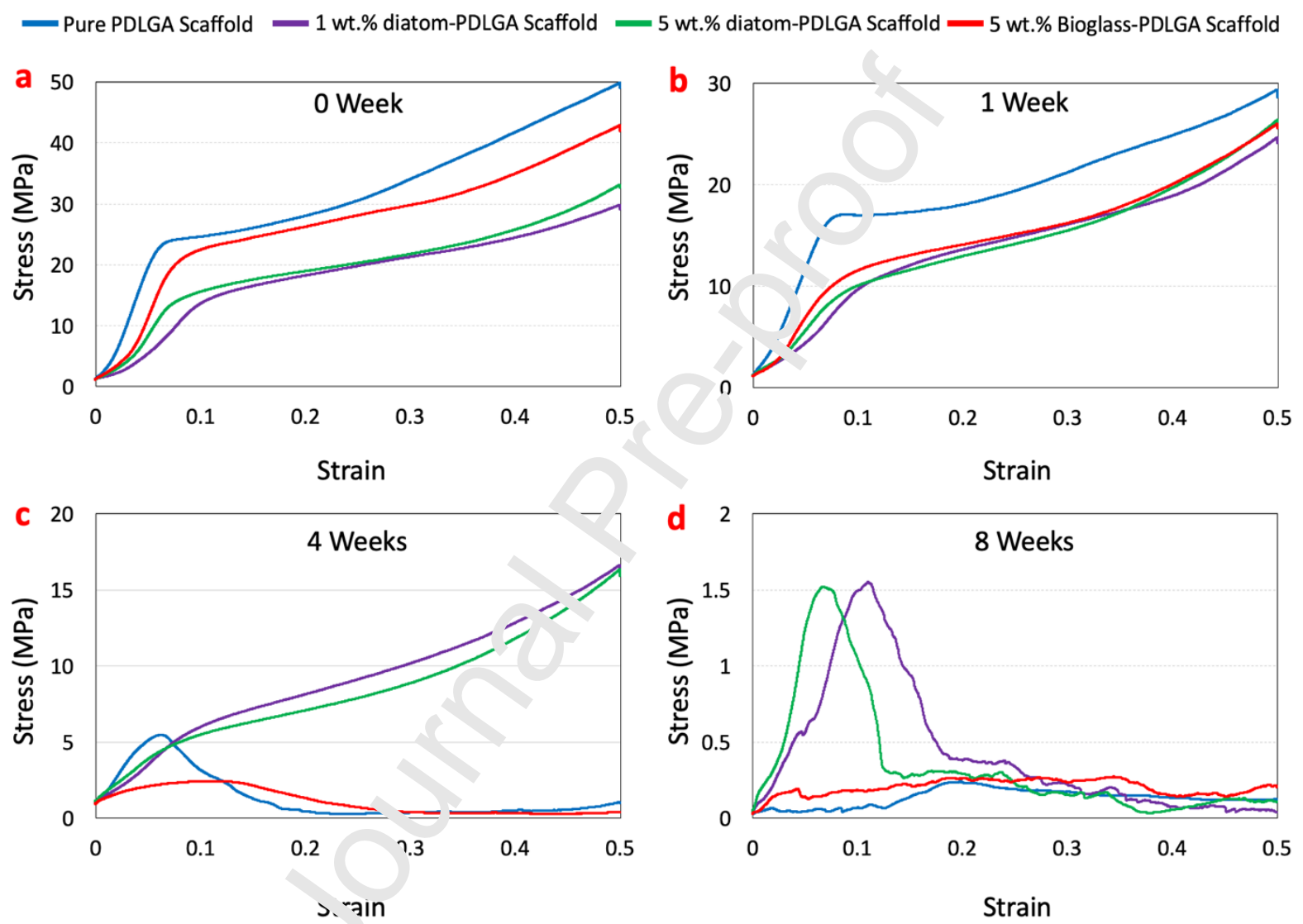

Fig. 3. Typical compression curves from 3D printed scaffolds after (a) 0 week, (b) 1 week, (c) 4 weeks, (d) 8 weeks. Blue line (pure PDLGA scaffold), red line (5 wt.\% Bioglass-PDLGA scaffold), purple line (1 wt.\% diatom-PDLGA scaffold) and green line (5 wt.\% diatom-PDLGA scaffold).

After one week's immersion in PBS solution, all the scaffolds showed a significant reduction in compressive strength but followed the same general trend as week 0 (Fig. 5b). After week 4 (Fig. 5c), pure PDLGA scaffold and 5 wt.\% Bioglass-PDLGA scaffolds showed a significant drop in stress at 0.06 and 0.11 strain respectively, whereas both diatom-scaffold concentrations followed the same trend but with a drop in overall compressive strength. At 
week 8 (Fig 5 d.) the compressive strength of all scaffold groups was significantly compromised, however, both diatom groups maintained measurable compressive strength (1.5 MPa) up to approximately $0.1 \%$ strain.
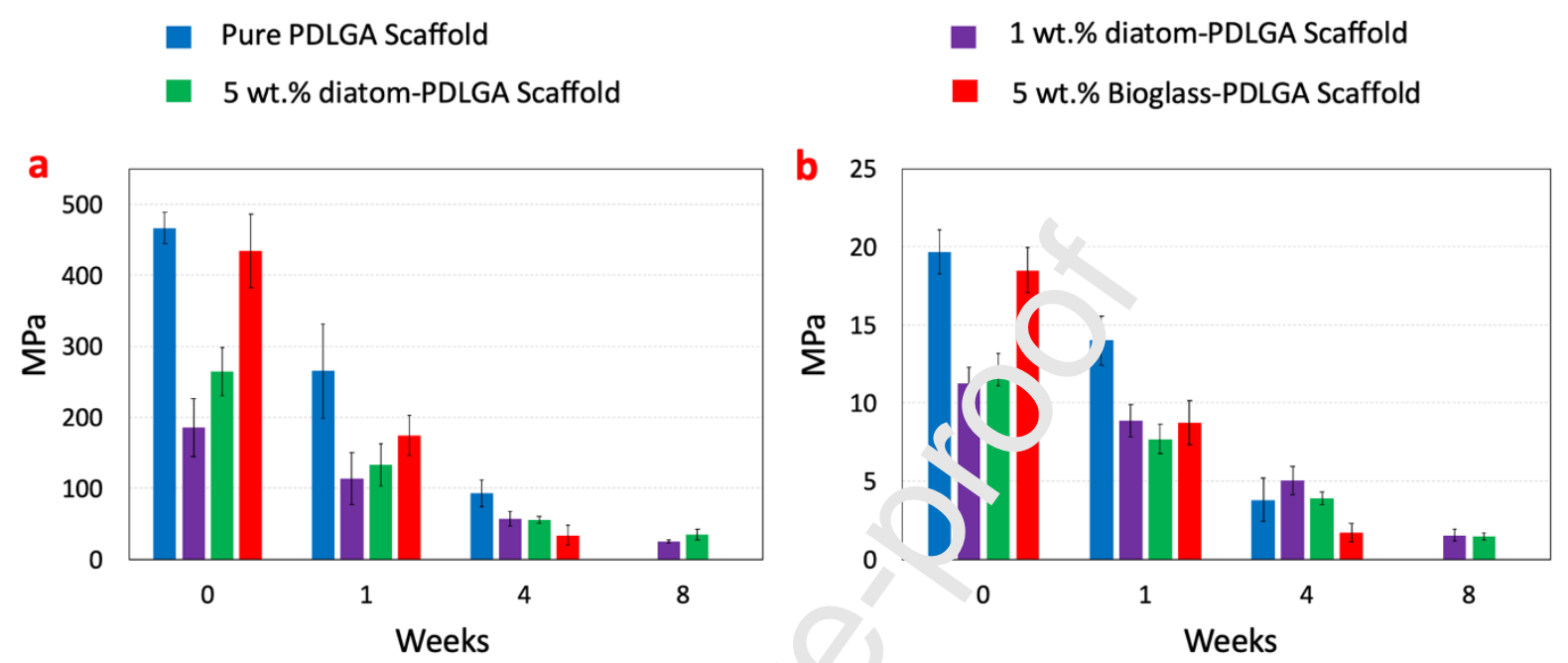

Fig. 4. The results from Compression test (a) Av _rag : Young's modulus, (b) Average yield stress

A summary of the compressive iai iur each scaffold group is shown in Fig 6 . The results showed that 1 wt.\% diatom DL ᄀA scaffold and 5 wt.\% diatom-PDLGA scaffold maintained their Young's moduli an' y y la strength up to 8 weeks immersion in PBS solution. Whereas, both pure PDLGA scaffol I and 5 wt.\% Bioglass-PDLGA scaffold groups were very fragile to test beyond week 4. Prior to immersion of the scaffolds into PBS solution (0-week), pure PDLGA scaffold exhibited the largest average Young's modulus at $466( \pm 22) \mathrm{MPa}$, followed by 5 wt.\% Bioglass-PDLGA scaffold with a Young's modulus of $434( \pm 51)$ MPa. The addition of diatoms however, both $1 \mathrm{wt} . \%$ and $5 \mathrm{wt} . \%$ was found to significantly reduce the Young's modulus to $186( \pm 40) \mathrm{MPa}$ and $264( \pm 34) \mathrm{MPa}$ respectively compared to the pure-PDLGA scaffold group. However, after week 4 the 5 wt.\% Bioglass-PDLGA scaffold groups became 
the weakest scaffold group with the Young's modulus dropping to $34( \pm 13) \mathrm{MPa}$. The 5 wt. $\%$ Bioglass scaffold groups demonstrated the fastest reduction to $90 \%$ of the Young's modulus in all four groups tested in just 4 weeks. This results are also comparable with a previous study by Liu et al., who reported the mechanical response of bioglass scaffolds rapidly changed within 4 weeks ${ }^{78}$.

Fig. $6 b$, the average yield stress data from the compression $t_{-}{ }^{+}$. showed a similar trend to the average Young's modulus. Diatom-PDLGA scaffolds mair 'ai' ied some yield stress up to week 8, whereas, the pure PDLGA scaffold and 5 vt.\% Bioglass-PDLGA scaffold only maintained its yield stress up to week 4 . This was und to be a statistically significant change between week 4 and $8(P=0.78)$. Bo.t. $d$ atom-PDLGA scaffold groups kept their shapes during the compression test up to veek 4 whereas, the pure PDLGA scaffold and 5 wt.\% Bioglass-PDLGA scaffold had no , eaningful data after week 1. The addition of diatom biosilica at concentrations of $1 \ldots+\% \times 5$ wt.\% did not initially enhance the compressive strength of PDLGA when $\mathrm{cnn}_{1}$; $a$ red to the pure PDLGA control. However, both diatomPDLGA scaffolds mainta; $几$ uieir mechanical strength for a long period of time, which is advantageous in bone re, air, as bone tissue requires 12 weeks to heal ${ }^{79-81}$. This is likely to be a result of the diatom biosilica filler which in a previous study by Han et al., were found to inhibit thermal degradation of the PDLGA. 


\subsection{Degradation Study via NMR}

${ }^{13} \mathrm{C}$ NMR analysis was carried out on scaffold solutions to investigate the change in the polymer at a molecular level during degradation. Fig. 7 shows the ${ }^{13} \mathrm{C}$ NMR spectra of the different scaffold groups with respect to time.

In the monomeric form the three carbon atoms in the structure give characteristic chemical shifts at $20 \mathrm{ppm}, 66 \mathrm{ppm}$ and $179 \mathrm{ppm}$ displayed in Table 3. The chemical shifts observed herein correspond well to those observed previously in $\mathrm{tl}$ e li erature ${ }^{81}$. There is a wide variation in electronegativity across the molecule whic i s:" shifts. When in the polymeric form there is a slighi ha' ge in the electron densities across the molecule and therefore a shift in ppm c's be observed upon polymerisation or breakdown. This phenomenon makes ${ }^{13} \mathrm{i} \wedge \mathrm{VR}$ an ideal tool for observing polymeric break down at the molecular level. 
Table 3. Structure and respective chemical shift measured in ppm of key lactic acid monomeric and polymeric ${ }^{13} \mathrm{C}$ peaks.

\begin{tabular}{|l|c|}
\hline Structure & Chemical shift (ppm) \\
\hline & \\
\hline
\end{tabular}

Resonances at $168 \mathrm{ppm}$ and $t \supset \mathrm{ppm}$ are attributed to the carbonyl and $\beta-C$ peak in the glycolic acid compon nt of che polymer chain, which has been shown previously by Essen et al. $^{82}$. The peaks corresponding to the lactic acid monomer started to become apparent in week 8 for the pure PDLGA scaffolds. This corresponds well with the drop in $\mathrm{pH}$ observed after 6 weeks shown in Figure 3. In contrast, the analysis of diatom-PDLGA and BioglassPDLGA did not show peaks for the monomeric units until week 16 . This would suggest the monomer lactic acid was released from the PDLGA polymer chain after 8 weeks in PBS solution for pure PDLGA scaffold groups, whereas the addition of diatom and Bioglass groups the silica appears to inhibit the release lactic acid until week 16. This supports earlier 
data Table 2 and Fig. 3 on pH/silica ion release that the addition of the diatoms delayed the onset of degradation compared to pure PDLGA. Both biogass and diatom silica have distinctly different material attributes, e.g. surface area, pore size, yet both silica groups have been shown to inhibit the release of lactic acid from PDLGA. The most plausible explanation is hydrogen bonding between functional group/polar atoms in the PDLGA and the surface of the silica. Zhou et al., ${ }^{83}$ reported similar bonding interactions between dry composites of PDLLA and HA that were moulded together. Th ' $v$ observed hydrogen bonding between $\mathrm{C}=\mathrm{O}$ groups in the PDLLA with the surface $\mathrm{P}-\mathrm{OH}$ gr ups in the HA. However, to the best of our knowledge there is little literature on the koı dir.g mechanism between PDLGA and Silica. To better understand the chemical inte, 'ctir ns occurring, further researcher is required, however, these results clearly show th th the addition of silica helps to slow the degradation rate of PDLGA, which is us' ful on wone tissue applications that requires up to 12 weeks to heal ${ }^{79-81}$. 
a

PDLGA Polymer Chain<smiles>CC(C)OCC(C)C(=O)OCC(C)C(=O)C(C)(C)O</smiles>

Lactic Acid

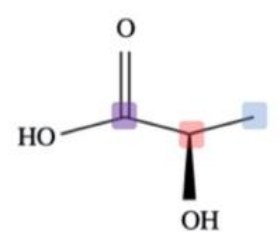

b

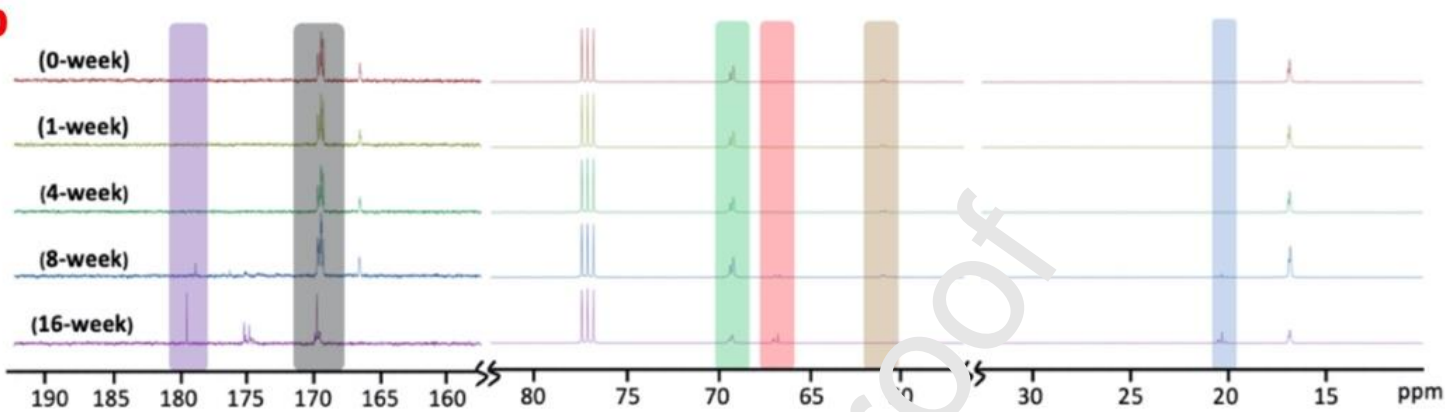

C

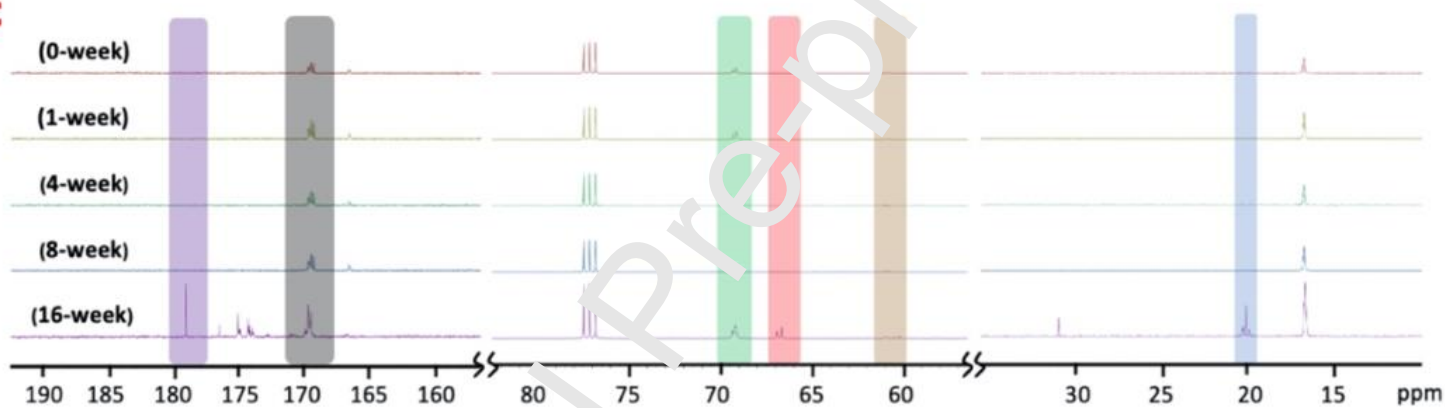

d

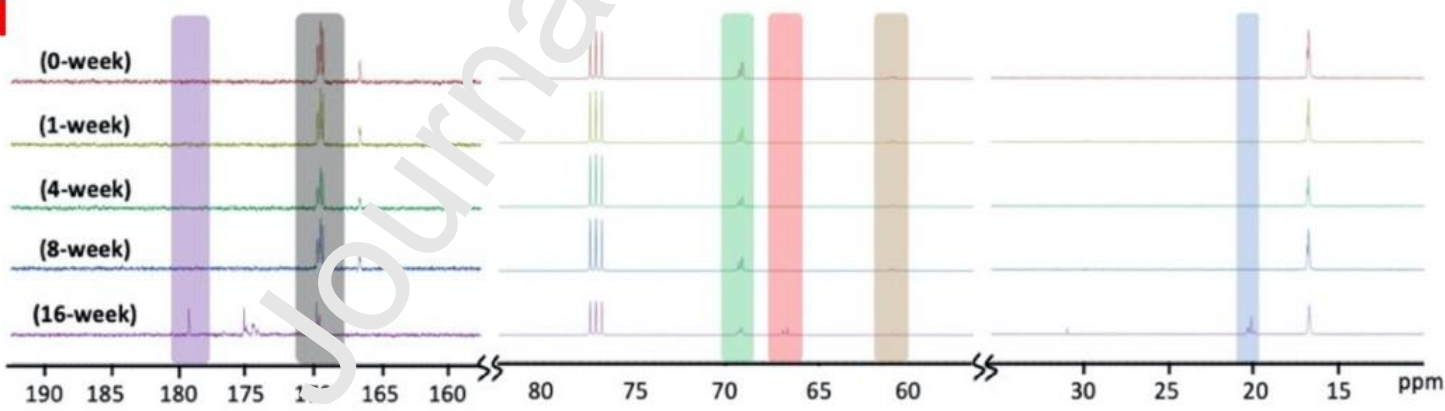

e

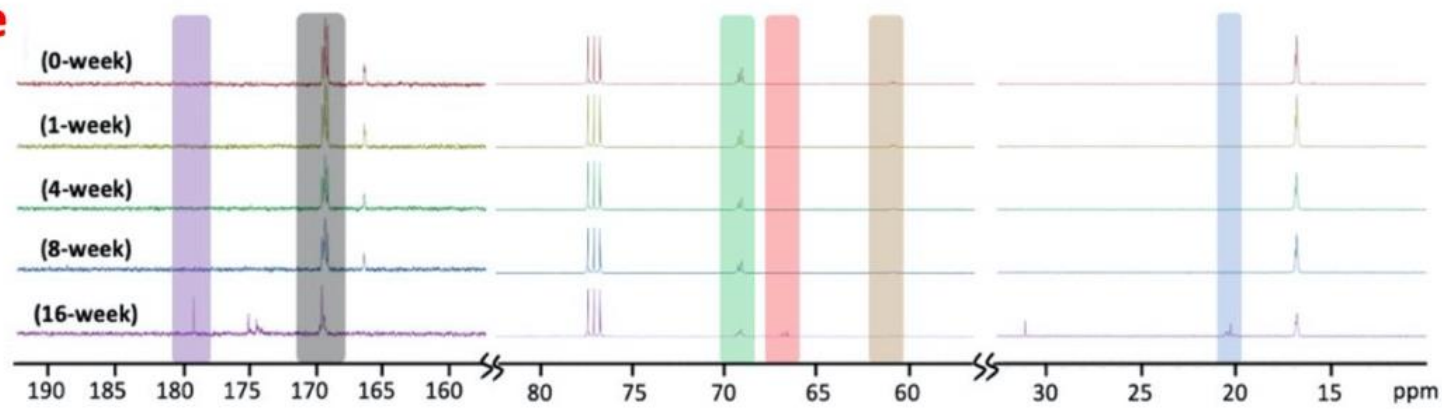

Fig. 5. ${ }^{13} \mathrm{C}$ NMR spectroscopy during the degradation study on (a) the skeletal formula of PDLGA polymer chain \& monomer lactic acid (b) Pure PDLGA Scaffolds, (c) 1 wt.\% diatom-PDLGA Scaffolds, (d) 5 wt.\% diatom-PDLGA Scaffolds, (e) 5 wt.\% Bioglass-PDLGA Scaffolds 


\section{Conclusion}

Diatom biosilica and Bioglass 45S5 PDLGA scaffolds were studied in PBS buffer to assess their Si release and compressive strength during in vitro degradation. The results suggested that diatom addition to PDLGA scaffolds reduces scaffold degradation whereby structural decomposition occurs up to 4 weeks later than pure PDLGA scaffolds. In term of the release rate of $\mathrm{Si}^{4+}$ ions, the concentration of $\mathrm{Si}^{4+}$ ions released from 5 wt.\% Bioglass-PDLGA scaffold was significantly higher than both diatom-PDLGA scaffolds (1 vt.\% \& 5 wt.\%), at comparable time points. For the bioglass composite the early burst $r \in$ eas : at week 2 may be a risk

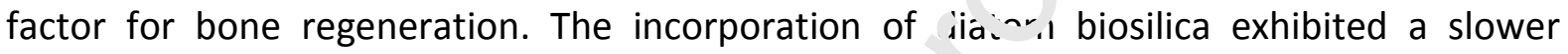
release rate on $\mathrm{Si}^{4+}$ ions than $45 \mathrm{~S} 5$ Bioglass from s $7 f f(\mathrm{dds}$. In addition, compression tests demonstrated that the compressive strengt 1 ir om diatom-PDLGA scaffolds could be maintained longer than pure PDLGA sc ifo $d$ ar.d 5 wt.\% Bioglass-PDLGA scaffold, which is advantageous in bone repair. This $p_{\mathbf{1}}$-longed compressive strength is mostly a result of the silica ions inhibiting the degradation of the PDLGA. For scaffolds it is critical that strength is maintained until tissue has $\Sigma$ ?ne $e_{1}$ ted and developed structure to the point where the scaffold support is no longe, rer, uired.

\section{Acknowledgements:}

Funding by Department of Communications, Marine and Natural Resources, Ireland (Beaufort Marine Biodiscovery Programme). The authors would like to acknowledge Mark Billham from Mechanical Engineering for their help with twin extrusion and Donal Moran in ASEP (School of Chemistry and Chemical Engineering) for running the ICP samples. The authors would like to thank Stephen Hull for editorial proofreading of this manuscript. 


\section{Reference:}

1. Wang, C. et al. 3D printing of bone tissue engineering scaffolds. Bioact. Mater. 5, 82-91 (2020).

2. Uskokovic, V. Nanostructured Platforms for the Sustained and Local Delivery of Antibiotics in the Treatment of Osteomyelitis. Crit. Rev. Ther. Drug Carrier Syst. 32, 1-59 (2015).

3. de Azevedo Gonçalves Mota, R. C., da Silva, E. O., de Liı n̊, F. F., de Menezes, L. R. \& Thiele, A. C. S. 3D Printed Scaffolds as a New Perspectiv ' for Bone Tissue Regeneration: Literature Review. Mater. Sci. Appl. 07, 430-452 (2C16;

4. Hutmacher, D. W., Schantz, J. T., Lam, C. X. F., T. ᄀ, K C. \& Lim, T. C. State of the art and future directions of scaffold-based bone er gi' $€$ ering from a biomaterials perspective. J. Tissue Eng. Regen. Med. 1, 245-260, 20, 7).

5. Bose, S., Vahabzadeh, S. \& Ba ^dyopadhyay, A. Bone tissue engineering using 3D printing. Mater. Today 16, 496-j’/4 (2013).

6. Valino, A. D. et al. Advar'es 1.: 3D printing of thermoplastic polymer composites and nanocomposites. Proa. i’n n. Sci. 98, 101162 (2019).

7. Little, H., Clarke, S. ^., Cunningham, E. \& Buchanan, F. Process-induced degradation of bioresorbable PDLGA in bone tissue scaffold production. J. Mater. Sci. Mater. Med. 29, (2018).

8. Wang, X., Jiang, M., Zhou, Z., Gou, J. \& Hui, D. 3D printing of polymer matrix composites: A review and prospective. Compos. Part B Eng. 110, 442-458 (2017).

9. Tofail, S. A. M. et al. Additive manufacturing: scientific and technological challenges, market uptake and opportunities. Mater. Today 21, 22-37 (2018). 
10. Daminabo, S. C., Goel, S., Grammatikos, S. A., Nezhad, H. Y. \& Thakur, V. K. Fused deposition modeling-based additive manufacturing (3D printing): techniques for polymer material systems. Mater. Today Chem. 16, 100248 (2020).

11. Bruyas, A. et al. Systematic characterization of 3D-printed PCL/ $\beta$-TCP scaffolds for biomedical devices and bone tissue engineering: Influence of composition and porosity. J. Mater. Res. 33, 1948-1959 (2018).

12. Niaza, K. V., Senatov, F. S., Kaloshkin, S. D., Maksimkin, A. V. \& Chukov, D. I. 3D-printed scaffolds based on PLA/HA nanocomposites for trabecu, эr $b$, ne reconstruction. J. Phys. Conf. Ser. 741, 012068 (2016).

13. Zein, I., Hutmacher, D. W., Tan, K. C. \& Teoh, S. H. f used deposition modeling of novel scaffold architectures for tissue engineeril $g$ a plications. Biomaterials 23, 1169-1185 (2002).

14. Kroeze, R., Helder, M., Govaert, '. \& Smit, T. Biodegradable Polymers in Bone Tissue Engineering. Materials 2, 833-8̄', ( '009).

15. D'Avila Carvalho Erbetta, C. Jynthesis and Characterization of Poly(D,L-Lactide-coGlycolide) Copolymer. J. . 3ir mater. Nanobiotechnology 03, 208-225 (2012).

16. Jain, S., Fuoco, T., r. sın, M. A., Mustafa, K. \& Finne-Wistrand, A. Printability and Critical Insight into Polymer Properties during Direct-Extrusion Based 3D Printing of Medical Grade Polylactide and Copolyesters. Biomacromolecules 21, 388-396 (2020).

17. Luzuriaga, M. A., Berry, D. R., Reagan, J. C., Smaldone, R. A. \& Gassensmith, J. J. Biodegradable 3D printed polymer microneedles for transdermal drug delivery. Lab. Chip 18, 1223-1230 (2018).

18. Tappa, K. \& Jammalamadaka, U. Novel Biomaterials Used in Medical 3D Printing Techniques. J. Funct. Biomater. 9, 17 (2018). 
19. Shuai, C. et al. Organic montmorillonite produced an interlayer locking effect in a polymer scaffold to enhance interfacial bonding. Mater. Chem. Front. 4, 2398-2408 (2020).

20. Shuai, C., Yang, W., Feng, P., Peng, S. \& Pan, H. Accelerated degradation of HAP/PLLA bone scaffold by PGA blending facilitates bioactivity and osteoconductivity. Bioact. Mater. 6, 490-502 (2021).

21. Feng, P. et al. Graphene oxide-driven interfacial coupling in laser 3D printed PEEK/PVA scaffolds for bone regeneration. Virtual Phys. Prototyp. 15, 2. 1-226 (2020).

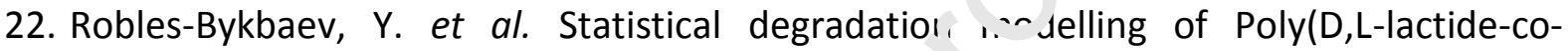
glycolide) copolymers for bioscaffold application. PL JS ONE 13, e0204004 (2018).

23. Athanasiou, K., Agrawal, C., Barber, F. \& B $\mathrm{rr}^{\prime} \cdot \mathrm{n}$ rt, S. Orthopaedic applications for PLAPGA biodegradable polymers. Arthre jc. . Ar ihrosc. Relat. Surg. 14, 726-737 (1998).

24. Gentile, P., Chiono, V., Carmay. ola, I. \& Hatton, P. An Overview of Poly(lactic-coglycolic) Acid (PLGA)-Based Biorn it frials for Bone Tissue Engineering. Int. J. Mol. Sci. 15, 3640-3659 (2014).

25. Rasoulianboroujeni, M. 't al. Development of 3D-printed PLGA/TiO2 nanocomposite scaffolds for bone tissue engineering applications. Mater. Sci. Eng. C 96, 105-113 (2019).

26. Makadia, H. K. \& Siegel, S. J. Poly Lactic-co-Glycolic Acid (PLGA) as Biodegradable Controlled Drug Delivery Carrier. Polymers 3, 1377-1397 (2011).

27. Jain, R. A. The manufacturing techniques of various drug loaded biodegradable poly(lactide-co-glycolide) (PLGA) devices. Biomaterials 21, 2475-2490 (2000). 
28. Ramanlal Chaudhari, K. et al. Bone metastasis targeting: A novel approach to reach bone using Zoledronate anchored PLGA nanoparticle as carrier system loaded with Docetaxel. J. Controlled Release 158, 470-478 (2012).

29. Tiainen, J., Soini, Y., Törmälä, P., Waris, T. \& Ashammakhi, N. Self-reinforced polylactide/polyglycolide $80 / 20$ screws take more than $1 \frac{1}{2}$ years to resorb in rabbit cranial bone: PLGA takes more than $1 \frac{1}{2}$ Years to Resorb Completely. J. Biomed. Mater. Res. B Appl. Biomater. 70B, 49-55 (2004).

30. Yi, H., Ur Rehman, F., Zhao, C., Liu, B. \& He, N. Recent adv inces in nano scaffolds for bone repair. Bone Res. 4, 16050 (2016).

31. Maçon, A. L. B. et al. Ductile silica/methacrylate . vbr ds for bone regeneration. J. Mater. Chem. B 4, 6032-6042 (2016).

32. Xu, H. H. K., Smith, D. T. \& Simon C. J. Jirong and bioactive composites containing nano-silica-fused whiskers for bo ' a repair. Biomaterials 25, 4615-4626 (2004).

33. JUGDAOHSINGH, R. SILICON A,V') SONE HEALTH. The Journal of Nutrition, Health \& Aging. 11 (2), 99-110 (200\%).

34. Rodella, L. F., Bonazza, Y Labanca, M., Lonati, C. \& Rezzani, R. A REVIEW OF THE EFFECTS OF DIETAı、 JILICON INTAKE ON BONE HOMEOSTASIS AND REGENERATION. $J$ Nutr Health Aging 18, 7 (2014).

35. Götz, W., Tobiasch, E., Witzleben, S. \& Schulze, M. Effects of Silicon Compounds on Biomineralization, Osteogenesis, and Hard Tissue Formation. Pharmaceutics 11, 117 (2019).

36. Szurkowska, K. \& Kolmas, J. Hydroxyapatites enriched in silicon - Bioceramic materials for biomedical and pharmaceutical applications. Prog. Nat. Sci. Mater. Int. 27, 401-409 (2017). 
37. Hench LL, Xynos ID, Polak JM. Bioactive glasses for in situ tissue regeneration. Journal of Biomaterials Science Polymer Edition 15(4):543-62 (2004).

38. Mieszawska, A. J. et al. Osteoinductive silk-silica composite biomaterials for bone regeneration. Biomaterials 31, 8902-8910 (2010).

39. Porter, A. E., Patel, N., Skepper, J. N., Best, S. M. \& Bonfield, W. Effect of sintered silicate-substituted hydroxyapatite on remodelling processes at the bone-implant interface. Biomaterials 25, 3303-3314 (2004).

40. Pietak, A. M., Reid, J. W., Stott, M. J. \& Sayer, M. Sili on ubstitution in the calcium phosphate bioceramics. Biomaterials 28, 4023-403: ( $<n /$ ).

41. Yang, Y. et al. Laser additive manufacturing ( $\mathrm{C}^{\mathrm{s}}$-based composite with improved degradation behaviour. Virtual Phys. Protot if. 25, 278-293 (2020).

42. Baino, F. \& Fiume, E. 3D Printing of Hitiarchical Scaffolds Based on Mesoporous Bioactive Glasses (MBGs) - Funda nentals and Applications. Materials 13, 1688 (2020).

43. Simpson, R. L. et al. A comparat ve study of the effects of different bioactive fillers in PLGA matrix composites - nd 'heir suitability as bone substitute materials: A thermomechanical and in vitru ir vestigation. J. Mech. Behav. Biomed. Mater. 50, 277-289 (2015).

44. Fu, Q., Saiz, E., Rahaman, M. N. \& Tomsia, A. P. Bioactive glass scaffolds for bone tissue engineering: state of the art and future perspectives. Mater. Sci. Eng. C 31, 1245-1256 (2011).

45. Le, T. D. H. et al. Processing and characterization of diatom nanoparticles and microparticles as potential source of silicon for bone tissue engineering. Mater. Sci. Eng. C 59, 471-479 (2016). 
46. Walsh, P. J., Clarke, S. A., Julius, M. \& Messersmith, P. B. Exploratory Testing of Diatom Silica to Map the Role of Material Attributes on Cell Fate. Sci. Rep. 7, (2017).

47. Schwalfenberg, G. K. The Alkaline Diet: Is There Evidence That an Alkaline pH Diet Benefits Health? J. Environ. Public Health 2012, 1-7 (2012).

48. Cheng, G. et al. Zwitterionic carboxybetaine polymer surfaces and their resistance to long-term biofilm formation. Biomaterials 30, 5234-5240 (2009).

49. Shahin-Shamsabadi, A. et al. Mechanical, material, and biological study of a PCL/bioactive glass bone scaffold: Importance of viscot last ity. Mater. Sci. Eng. C 90, 280-288 (2018).

50. Distler, T. et al. Polymer-Bioactive Glass C $>m r$ osite Filaments for 3D Scaffold Manufacturing by Fused Deposition Mode'in’s: Fabrication and Characterization. Front. Bioeng. Biotechnol. 8, 552 (2020).

51. Bohner, M. Silicon-substituted c.lcium phosphates - A critical view. Biomaterials. 30 6403-6406 (2009).

52. Bramfeldt, H., Sarazin, P. \& Veı mette, P. Characterization, degradation, and mechanical strength of poly(D,L-laitir e-co-e-caprolactone)-poly(ethylene glycol)-poly(D,L-lactideco- $\varepsilon$-caprolactone). ' biomed. Mater. Res. A 83A, 503-511 (2007).

53. Petisco-Ferrero, S., Etxeberria, A. \& Sarasua, J. R. Mechanical properties and state of miscibility in poly(racD,L-lactide-co-glycolide)/(L-lactide-co-e-caprolactone) blends. J. Mech. Behav. Biomed. Mater. 71, 372-382 (2017).

54. Kiss, K. T., Klee, R., Ector, L. \& Ács, É. Centric diatoms of large rivers and tributaries in Hungary: morphology and biogeographic distribution. Acta Bot. Croat. 71, 311-363 (2012). 
55. Cavalcante, K. P., Tremarin, P. I. \& Ludwig, T. A. V. Taxonomic studies of centric diatoms (Diatomeae): unusual nanoplanktonic forms and new records for Brazil. Acta Bot. Bras. 27, 237-251 (2013).

56. Hevia-Orube, J. et al. Molecular and morphological analyses of solitary forms of brackish Thalassiosiroid diatoms (Coscinodiscophyceae), with emphasis on their phenotypic plasticity. Eur. J. Phycol. 51, 11-30 (2016).

57. Agrawal, C. M., Niederauer, G. G. \& Athanasiou, K. A. Fabr mation and Characterization of PLA-PGA Orthopedic Implants. Tissue Eng. 1, 241-252 (1. 195)

58. Fukuzaki, H. et al. A new biodegradable copolymer \& olycolic acid and lactones with relatively low molecular weight prepared by di, oct opolycondensation in the absence of catalysts. J. Biomed. Mater. Res. 25, 315-37.8 (1991).

59. Wu, L. \& Ding, J. In vitro degradati un if tıree-dimensional porous poly(d,I-lactide-coglycolide) scaffolds for tissue engineering. Biomaterials 25, 5821-5830 (2004).

60. Grayson, A. C. R., Cima, M. J. \& Lē ng ar, R. Size and temperature effects on poly(lactic-coglycolic acid) degradation ani microreservoir device performance. Biomaterials 26, 2137-2145 (2005).

61. Ara, M., Watanabe, Mı. \& Imai, Y. Effect of blending calcium compounds on hydrolytic degradation of poly(dl-lactic acid-co-glycolic acid). Biomaterials 23, 2479-2483 (2002).

62. Jang, H. J. et al. Effect of various shaped magnesium hydroxide particles on mechanical and biological properties of poly(lactic- co -glycolic acid) composites. J. Ind. Eng. Chem. 59, 266-276 (2018).

63. Liu, H., Slamovich, E. B. \& Webster, T. J. Less harmful acidic degradation of poly(lacticco-glycolic acid) bone tissue engineering scaffolds through titania nanoparticle addition. Int. J. Nanomedicine 1, 541-545 (2006). 
64. Farahani, T. D., Entezami, A. A., Mobedi, H. \& Abtahi, M. Degradation of Poly(D,L-lactideco-glycolide) 50:50 Implant in Aqueous Medium. Iran. Polym. J. 14, 12 (2005).

65. Begum, S., Johnson, W. E., Worthington, T. \& Martin, R. A. The influence of $p H$ and fluid dynamics on the antibacterial efficacy of $45 S 5$ Bioglass. Biomed. Mater. 11, 015006 (2016).

66. Elisa Fiume, Jacopo Barberi, Enrica Verné \& Francesco Baino. Bioactive Glasses: From Parent 45S5 Composition to Scaffold-Assisted Tissue Hoaling Therapies. J. Funct. Biomater. 9, 24 (2018).

67. Kumar, A., Murugavel, S., Aditya, A. \& Boccaccin , r. r.. Mesoporous 45S5 bioactive glass: synthesis, in vitro dissolution and biomint. liz tion behavior. J. Mater. Chem. B 5, 8786-8798 (2017).

68. Zandi Karimi, A., Rezabeigi, E. \& Dr -W, R. ค. L. Crystallization behavior of combeite in $45 S 5$ Bioglass ${ }^{\circledR}$ via controlled hea: treatment. J. Non-Cryst. Solids 502, 176-183 (2018).

69. Holy, C. E., Dang, S. M., Davies, . . \& Shoichet, M. S. In vitro degradation of a novel poly(lactide-co-glycolide) 7ร/2; foam. Biomaterials 20, 1177-1185 (1999).

70. Sepulveda, P., Jones, J. $\therefore$ \&. Hench, L. L. Characterization of melt-derived $45 S 5$ and solgel-derived 58S bio -tive glasses. J. Biomed. Mater. Res. 58, 734-740 (2001).

71. Dashnyam, K. et al. A mini review focused on the proangiogenic role of silicate ions released from silicon-containing biomaterials. J. Tissue Eng. 8, 1-13 (2017).

72. Ruangsuriya, J., Robertson, Z., Annaz, B. \& Gibson, I. R. Si ion concentration affects osteoblast gene expression. European Cells and Materials 18, 93 (2009).

73. Han, P., Wu, C. \& Xiao, Y. The effect of silicate ions on proliferation, osteogenic differentiation and cell signalling pathways (WNT and SHH) of bone marrow stromal cells. Biomater Sci 1, 379-392 (2013). 
74. Chengtie Wu, Jiang Chang, Yin Xiao. Advanced Bioactive Inorganic Materials for Bone Regeneration and Drug Delivery. CRC Press (2013).

75. Roger Narayan. Encyclopedia of Biomedical Engineering. Elsevier (2018).

76. Ginebra, M. P. Cements as bone repair materials. Bone Repair Biomaterials, Elsevier 271-308 ( 2009).

77. Velasco, M. A., Narváez-Tovar, C. A. \& Garzón-Alvarado, D. A. Design, Materials, and Mechanobiology of Biodegradable Scaffolds for Bone Tis ile Engineering. BioMed Res. Int. 2015, 1-21 (2015).

78. Liu, X., Rahaman, M. N., Hilmas, G. E. \& Bal, B. S. N. ^r'.lanical properties of bioactive

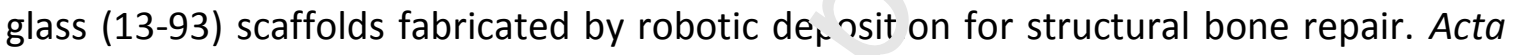
Biomater. 9, 7025-7034 (2013).

79. Werntz, J. R. et al. Qualitative and $a^{\prime}$ 'an itatıve analysis of orthotopic bone regeneration by marrow. J. Orthop. Res. 14, 8593 (1996).

80. Moghadam, H. G., Sándor, G. K. B , I lolmes, H. H. I. \& Clokie, C. M. L. Histomorphometric evaluation of bone regene' atic.i using allogeneic and alloplastic bone substitutes. J. Oral Maxillofac. Surg. 62, 20< -7:.3 (2004).

81. Kentleach, J., Kaigı $、$, D., Wang, Z., Krebsbach, P. \& Mooney, D. Coating of VEGFreleasing scaffolds with bioactive glass for angiogenesis and bone regeneration. Biomaterials 27, 3249-3255 (2006).

82. Göktürk, E., Pemba, A. G. \& Miller, S. A. Polyglycolic acid from the direct polymerization of renewable C1 feedstocks. Polym. Chem. 6, 3918-3925 (2015).

83. Zhou, S. et al. Hydrogen Bonding Interaction of Poly( D, L -Lactide)/hydroxyapatite Nanocomposites. Chem. Mater. 19, 247-253 (2007). 


\section{Author Statement}

R. Han (RH), F. Buchanan (FB), M. Julius (MJ), PJ Walsh (PJW)

RH, FB, PJW - Conceptualization; RH - Data curation; RH, PJW - Formal analysis; MJ Statistical analysis, RH (Self-funded PhD with 1-year Beaufort Marine Biodiscovery Programme - FB) Funding acquisition; RH, FB, PJW - Methodology; RH Writing - original draft; All authors - Writing - review \& editing. 
Highlights

1. The compressive strength of Diatom-PDLGA scaffolds were found to maintain their strength for longer than either pure PDLGA scaffolds or 5 wt.\% Bioglass scaffolds.

2. Chemical analysis using ${ }^{13} \mathrm{C}$ NMR showed that scaffolds with diatom silica had less degradation than pure or bioglass-containing scaffolds at comparable time-points.

3. The release rate of $\mathrm{Si}^{4+}$ ions from diatom-PDLGA scaffolds was found to increase exponentially with respect to time 